\title{
Russian Federation
}

National Cancer Institute

\section{Source}

National Cancer Institute. Russian Federation. NCI Thesaurus. Code C17111.

A country in northern Asia, bordering the Arctic Ocean, between Europe and the North Pacific Ocean. 